\title{
Viability and management of an endangered Capercaillie (Tetrao urogallus) metapopulation in the Jura Mountains, western Switzerland
}

\author{
SÉBASTIEN SACHOT ${ }^{1,2, *}$, NICOLAS PERRIN ${ }^{1}$ and \\ CORNELIS NEET ${ }^{2}$ \\ ${ }^{1}$ Laboratory for Conservation Biology, Department of Ecology and Evolution, University of Lau- \\ sanne, CH-1015 Lausanne, Switzerland; ${ }^{2}$ Centre de Conservation de la Faune et de la Nature, Chemin \\ du Marquisat 1, CH-1025 St-Sulpice, Switzerland; *Author for correspondence (e-mail: sebastien. \\ sachot@sffn.vd.ch; phone: +41-21-694-82-00; fax: +41-21-694-82-50)
}

Received 22 April 2004; accepted in revised form 7 January 2005

Key words: Capercaillie, Endangered species, Habitat, Population dynamics, Population viability analysis, Tetrao urogallus

\begin{abstract}
The populations of Capercaillie (Tetrao urogallus), the largest European grouse, have seriously declined during the last century over most of their distribution in western and central Europe. In the Jura mountains, the relict population is now isolated and critically endangered (about 500 breeding adults). We developed a simulation software (TetrasPool) that accounts for age and spatial structure as well as stochastic processes, to perform a viability analysis and explore management scenarios for this population, capitalizing on a 24 years-long series of field data. Simulations predict a marked decline and a significant extinction risk over the next century, largely due to environmental and demographic stochasticity (average values of life-history parameters would otherwise allow stability). Variances among scenarios mainly stem from uncertainties about the shape and intensity of density dependence. Uncertainty analyses suggest to focus conservation efforts on enhancing, not only adult survival (as often advocated for long-lived species), but also recruitment. The juvenile stage matters when local populations undergo extinctions, because it ensures connectivity and recolonization. Besides limiting human perturbations, a silvicultural strategy aimed at opening forest structure should improve the quality and surface of available patches, independent of their size and localization. Such measures are to be taken urgently, if the population is to be saved.
\end{abstract}

\section{Introduction}

Habitat loss and fragmentation is threatening an increasing number of species. Fragmentation breaks down large natural populations into series of small-sized demes, which are highly susceptible to stochastic fluctuations and local extinctions (Akçakaya and Baur 1996). This, however, does not necessarily lead to a global extinction: fragmented populations may survive for some time in disequilibrium dynamics, if the specific dispersal ability and landscape structure allows recolonization events to balance local extinction rates (Gutiérrez et al. 1999). Such metapopulation dynamics is becoming a central issue in conservation biology (Hanski et al. 1996). 
Population viability analyses (PVA) are aimed at assessing the extinction risk of focal populations within a specified time horizon, and to compare alternative management options (Bustamante 1996). The introduction of quantitative elements into risk assessment is indeed crucial if management decisions are to be made on a priori clear expectations of population responses, and not on the ease of implementation or accessibility of a life stage (Crouse et al. 1987).

Analytical approaches are only of limited help in this context: the simplifying assumptions made for tractability are normally incompatible with the complexity of real situations. Details of life-histories and spatial structures in particular can usually not be dealt with analytically, but have important consequences on populations (Hanski 1991). Computer simulations, as an alternative, have the potential to account for a great deal of biological realism. But they also incur some risks and limitations, due to their lack of generality, and to the difficulty of converting real-world complex interactions into a functional model (Reed et al. 1998). Introducing too much complexity in a model is not only useless, it may be detrimental. Sophisticated models may require too detailed field information without providing much additional insights. To be useful and reliable, PVAs require careful parameter estimations (Saether et al. 1998), which are often missing or imprecise for rare or endangered species. The trade-off between complexity and functionality is thus bound to depend on the characteristics of the species in concern, on the availability of data, and on the question addressed (Burgman et al. 1993).

Capercaillie (Tetrao urogallus), the largest European grouse, is listed as threatened in western, central and south-eastern Europe (IUCN 1996). Though the species still occupies most of its original range throughout northern Europe and Asia, western and central Europe populations have experienced important declines and local extinctions over the past decades, owing to habitat losses, habitat fragmentation and human disturbance (Storch 2000). Rainy conditions during egg incubation and young rearing, as well as predation (Storch 1991) can locally amplify population decline. Remnant populations are restricted to mountain regions where habitats are often isolated and fragmented (Blair et al. 1997).

The capercaillie is strictly associated with boreal or mountain forests with highly specific habitat requirements in terms of structure and composition that are in most cases best met by old stands (Picozzi et al. 1992). Bilberry (Vaccinium myrtillus) represents the major part of its summer diet, while in central Europe, fir (Abies alba) is required as winter food. Annual home range varies from 100 to 1000 ha (Gjerde and Wegge 1989; Ménoni 1991) for adults of both sexes according to local conditions. These characteristics, together with a high sensitivity to human perturbations (especially during the winter period and the reproductive season), make capercaillie an indicator of undisturbed forest ecosystems (Storch 1993).

In Switzerland, several populations have been extinct and capercaillie distribution showed a drastic reduction of 20.6\% between 1972-1976 and 19931996 (Schifferli et al. 1980; Schmid et al. 1998). The Jura Mountains, Schwytz 
Alps and Grison Alps are the only demes left in Switzerland with more than 100 birds (Schmid et al. 1998). As the result of cattle farming and silvicultural practices started as early as the 14th century (Leclercq 1987b), the distribution of capercaillie populations in the Jura mountains (lat. $47^{\circ} 25^{\prime} \mathrm{N}$; long. $6^{\circ} 42^{\prime} \mathrm{E}$ ) has long been patchy. It has, however, drastically regressed since the 1960s, being now restricted to altitudes $1200 \mathrm{~m}$ and above (up to $1550 \mathrm{~m}$ ). The remaining metapopulation is distributed over 35 forest patches, 24 of which in France (Montadert and Chamouton 1997) and 11 in Switzerland (Dändliker et al. 1993), covering $542 \mathrm{~km}^{2}$ in total. Population size is estimated at about 500 reproductive birds (Montadert and Chamouton 1997).

In Switzerland, concerns raised by capercaillie's rapid decline resulted in financial support for silvicultural practices that would improve its habitat conditions. Political pressure to invest money in a cost-effective way called for a comprehensive approach aimed at identifying crucial life-history stages and potential effects of habitat improvements.

In the present paper, we present a viability analysis for the endangered capercaillie metapopulation of the Jura mountains, Central Europe. Field studies on this focal population started in 1976. Its specific life-history parameters and decline are thus well documented. The analysis was performed on a series of computer simulations performed with the software TetrasPool 1.0.2, (Sachot 2000) specifically developed to make full use of the detailed information currently available on capercaillie biology. Our specific goals were to define crucial life-history stages, to explore the relative benefits of several management scenarios and to locate gaps in the knowledge of the species demography to focus future studies.

\section{Methods}

\section{Outline of the model}

TetrasPool was explicitly built to match capercaillie natural history, but would suit any species with similar life cycle. The model considers females only, assuming males are not limiting in lekking species. Time steps are annual, and age-structure is restricted to two classes (juveniles for the first year of life, adults thereafter), with different survival rates (Figure 1). Juveniles disperse away from the natal territory after fledging (autumn and early winter), then establish a breeding territory (Storch 1995). A single reproductive bout occurs per year, in which only a proportion of the females participate.

Under these assumptions, the finite rate of increase reads:

$$
\lambda=S_{a}+\operatorname{prf} S_{j}
$$

where $S_{a}$ is adult female survival, $S_{j}$ juvenile survival, $p$ the proportion of females breeding in any given year, $f$ their fecundity, and $r$ the primary sex ratio (proportion of females in broods). 


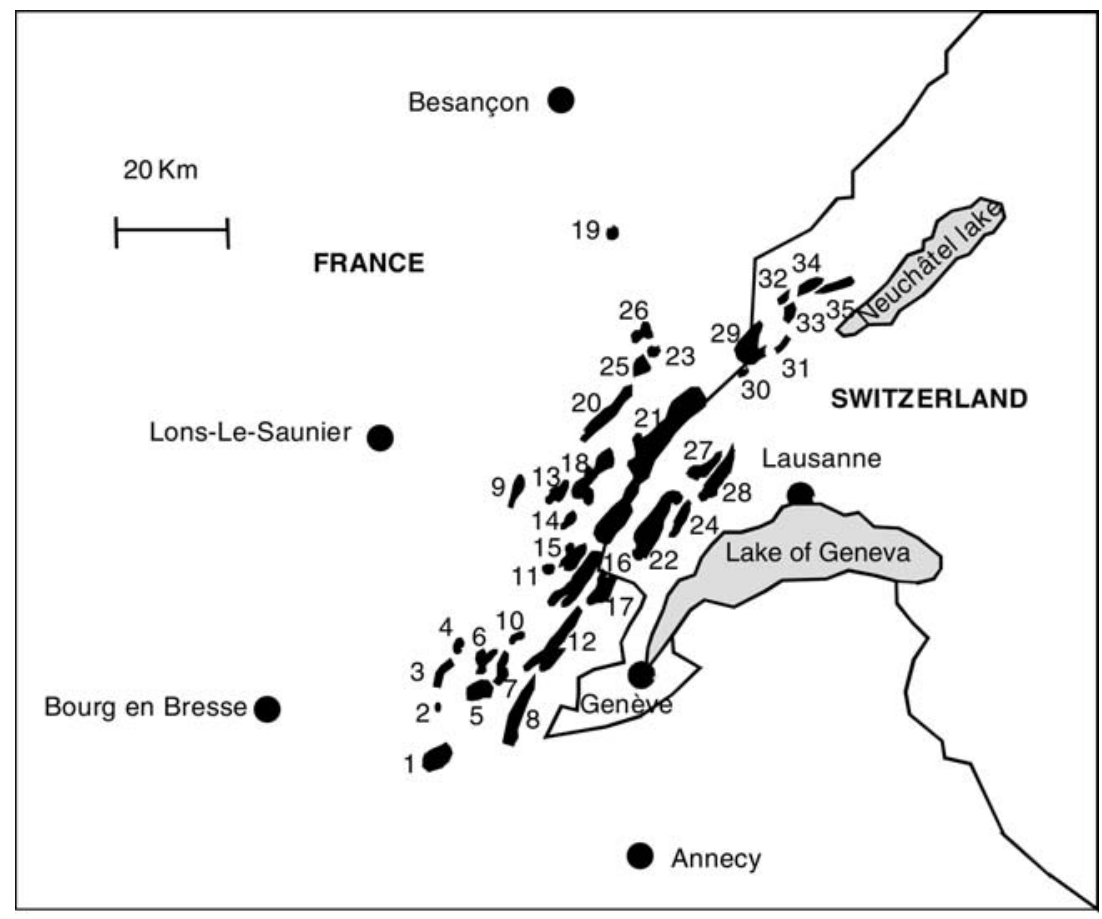

Figure 1. Locations of the 35 capercaillie populations in the Jura Mountains. Refer to Table 2 for relationships between population number, initial abundance and estimated carrying capacities.

\section{Local dynamics}

Density dependence in local dynamics most likely stems from the failure of young females to obtain a territory, which impairs their ensuing survival and breeding success (Ménoni 1991). We thus implemented density dependence through a negative effect of adult density on juvenile recruitment. The available evidence suggests a linear effect of density per capita rate of growth (Cattadori et al. 2000), but, owing to the scarcity of empirical data, both ceiling- and logistic relationships were explored. In the ceiling type, juvenile recruitment (in Eq. (1)) was kept constant at observed value (Table 1), baring stochastic variations, as long as local populations were below their capacity, and truncated otherwise. Under logistic control, recruitment declined linearly with density:

$$
S_{j, t}=S_{0}-\frac{S_{0}-\bar{S}}{K} N_{t},
$$

where $K$ is the local carrying capacity (number of breeding territories on the local patch), $N_{t}$ the local density of adult females for the year considered, $S_{j, t}$ 
Table 1. Baseline parameter estimates used in the simulations of capercaillie persistence in the Jura Mountains, western Switzerland.

\begin{tabular}{|c|c|c|}
\hline Parameter & Value $( \pm \mathrm{SD})$ & Source \\
\hline $\begin{array}{l}\text { Sex ratio (proportion of } \\
\text { female hatchlings) }\end{array}$ & 0.5 & Leclercq (1987) \\
\hline Fecundity & $7.54( \pm 0.6)$ & Derived from Leclercq (1987a) \\
\hline Proportion of reproductive females & $0.25( \pm 0.2)$ & $\begin{array}{l}\text { Derived from Leclercq (1987a) } \\
\text { and and Leclercq (unpublished data) }\end{array}$ \\
\hline Female juvenile survival & $0.19( \pm 0.15)$ & Leclercq (1987a) \\
\hline Female maximum juvenile survival & 0.3 & Storch $(2000)$ \\
\hline Female adult survival & $0.82( \pm 0.24)$ & Leclercq (1987a) \\
\hline Female summer home range size (ha) & 50 & Storch (1993), Ménoni (1991) \\
\hline Average dispersal distance (m) & 8000 & Wegge et al. (1981), Koivisto (1963) \\
\hline Dispersal rate $(\%)$ & $0.1( \pm 0.2)$ & Ménoni (1991) \\
\hline
\end{tabular}

the average recruitment for this year, $S_{0}$ the maximal recruitment (reached when adult density tends to 0 so that all breeding territories are available), and $\bar{S}$ the recruitment at equilibrium (recruitment probability when $N=K$, i.e., the value of $S_{j}$ that makes $\lambda=1$ in Eq. (1).

\section{Spatial structure}

The metapopulation consisted in a number of local populations with different carrying capacities but similar life-history parameters, baring stochasticity (see below). Juveniles dispersed from their natal patch with probability. Among the pool of juveniles dispersing from patch $i$, the probability of successfully attaining patch $j$ was modeled as:

$$
m_{i j}=\frac{1}{\pi} \operatorname{Arctan}\left(\frac{R_{j}}{D_{i j}}\right) e^{-D_{i j} / \bar{D}}
$$

where $R_{j}$ is the radius of the target population, $D_{i j}$ the distance between patch centroïds, and $\bar{D}$ the average dispersal distance. Thus, connectivity among patches increased with their size and proximity.

\section{Stochasticity}

Environmental stochasticity was introduced by sampling the patch-specific value of a parameter (e.g., dispersal probability) from a beta distribution, with mean and standard deviation defined for the whole metapopulation (Table 1). Demographic stochasticity was introduced by assigning individual status (i.e., 
whether the focal individual survived or not, reproduced or not, dispersed or not) from a binomial sampling, and individual fecundity from a Poisson sampling, with parameter set to the patch-specific value.

\section{Estimation of life-history parameters}

Fecundity was estimated as the mean number of eggs in all clutches $(n=28)$ discovered during field sampling of the French Jura population 21 (Figure 2) between 1976 and 1999.

Baseline demographic parameters estimations (Table 1) were issued from route census of this same population performed between the 15th and 30th of July (i.e., 3 months after egg laying) from 1976 to 2000 (Leclercq 1987c). A line of 3-8 persons arranged at $25 \mathrm{~m}$ intervals walked simultaneously through entire forest patches and counted flushed juveniles, adult males and adult females capercaillie. Age- and sex-undetermined birds were omitted from demographic parameters calculations.

The proportion of reproductive females was set to the average proportion of females observed with a brood during a census. The average survival rates of juveniles $\left(S_{j}\right)$ and adults $\left(S_{a}\right)$ used in Eq. (1) were estimated by Leclercq (1987c) from the linear regression:

$$
S_{t}=S_{a}-R_{t}\left(S_{a}-S_{j}\right)
$$

where $S(t)$ is the population average survival from year $t$ to $t+1$, calculated by dividing the number of adults at year $t+1$ by the total number of individuals (adults plus juveniles) at year $t$, and $R(t)$ is the proportion of juveniles at year $t$, calculated as the ratio of the number of juveniles to the total number of individuals (adults plus juveniles). Maximal juvenile survival rate $\left(S_{0}\right)$ was set to 0.3 according to (Storch 2000).

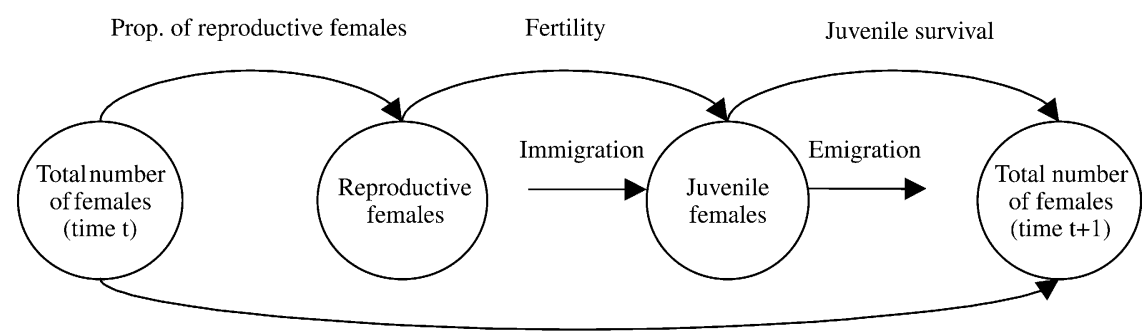

Adult survival

Figure 2. Annual life history traits of capercaillie females considered in the model. Fertility accounts for both fecundity and sex ratio. 
Local carrying capacities were calculated by dividing patch size by female spring home range (Sachot 2002; Table 2), estimated to be $c a 50$ ha during the breeding season (Ménoni 1994). In absence of local information on dispersal, we used values published from other West-European populations, namely an average juvenile dispersal distance of $8 \mathrm{~km}$ (Wegge et al. 1981) and a dispersal rate of 10\% (Ménoni 1991).

Initial abundance of males is the total number of males counted at the leks in each population during spring 2000. We assumed a 1:1 sex ratio in each population to extrapolate female initial abundance (Table 2).

Table 2. Capercaillie initial abundance (adult females only) and carrying capacity (K) for the 35 populations of the Jura Mountains.

\begin{tabular}{|c|c|c|}
\hline Population number & Initial abundance (female only) & $\mathrm{K}$ \\
\hline 1 & 1 & 17 \\
\hline 2 & 1 & 1 \\
\hline 3 & 1 & 6 \\
\hline 4 & 1 & 4 \\
\hline 5 & 7 & 16 \\
\hline 6 & 2 & 4 \\
\hline 7 & 6 & 6 \\
\hline 8 & 13 & 30 \\
\hline 9 & 3 & 3 \\
\hline 10 & 1 & 4 \\
\hline 11 & 1 & 3 \\
\hline 12 & 30 & 22 \\
\hline 13 & 3 & 9 \\
\hline 14 & 2 & 5 \\
\hline 15 & 7 & 8 \\
\hline 16 & 12 & 14 \\
\hline 17 & 12 & 14 \\
\hline 18 & 16 & 31 \\
\hline 19 & 1 & 3 \\
\hline 20 & 12 & 20 \\
\hline 21 & 64 & 117 \\
\hline 22 & 25 & 70 \\
\hline 23 & 1 & 2 \\
\hline 24 & 3 & 23 \\
\hline 25 & 3 & 6 \\
\hline 26 & 2 & 3 \\
\hline 27 & 6 & 24 \\
\hline 28 & 12 & 40 \\
\hline 29 & 4 & 8 \\
\hline 30 & 1 & 1 \\
\hline 31 & 1 & 1 \\
\hline 32 & 1 & 1 \\
\hline 33 & 1 & 5 \\
\hline 34 & 7 & 7 \\
\hline 35 & 4 & 10 \\
\hline
\end{tabular}


Simulation scenarios

We caution that these metrics should not be interpreted literally, because of the many assumptions necessary in any PVA model, but rather be used to compare the influence of parameters sets and enhancement scenarios on PVA predictions. A first set of simulations was run using the baseline demographic parameter values (Table 1) and initial population sizes (Table 2), with densitydependence of either ceiling- or logistic type. Further simulations were then conducted with one parameter changed at a time, all other parameters being held to their baseline value. The parameter changed was set to either a low or a high value, representing extreme estimates derived from a compilation of all known capercaillie data reported in published papers for other European populations (Höglund 1952; Koivisto 1963; Wegge et al. 1981, 1990; Moss and Oswald 1985; Leclercq 1987a, c; Moss and Weir 1987). Finally, we tested a series of ecological scenarios corresponding to changes in habitat availability and/or quality. The first scenario involved a yearly reduction of the carrying capacity by $0.43 \%$, which reflects habitat loss during the last decade (Sachot 2002; Sachot unpublished data). The other scenarios involved habitat enhancement. Present political context and financial resources make improvement of about half of the available area a realistic measure. Accordingly, our habitat enhancement scenarios consisted of a $50 \%$ increase of the surface of (1) all patches, as suggested by Ménoni (1994), (2) the two largest patches only, to explore the influence of potential source populations, sensus Burgman et al. (1993), (3) the 12 smallest patches only, to maintain population connectivity that may lead to recolonization of empty patches by immigration from other extant populations (Akçakaya and Baur 1996).

Cycles started with an initial number of females specified for each patch (Table 2), estimated at the onset of the breeding season. For each scenario, 1000 replicates, including both demographic and environmental stochasticity, were performed over 100 years, at which time frequency distributions, extinction probabilities as well as median time to extinction (for extinct runs), were computed.

\section{Results}

\section{Risk analysis}

Even though the deterministic rate of increase, calculated by inserting demographic parameter values (Table 1) in Eq. (1), would predict long term stability for the population, our stochastic and spatially structured simulations predict a significant decrease over time. The results of risk analysis with ceiling and logistic density dependence are presented in Table 3. Ceiling or logistic density dependence provided contrasted results in terms of extinction risk and time to extinction; logistic density dependence provided smaller extinction risks 


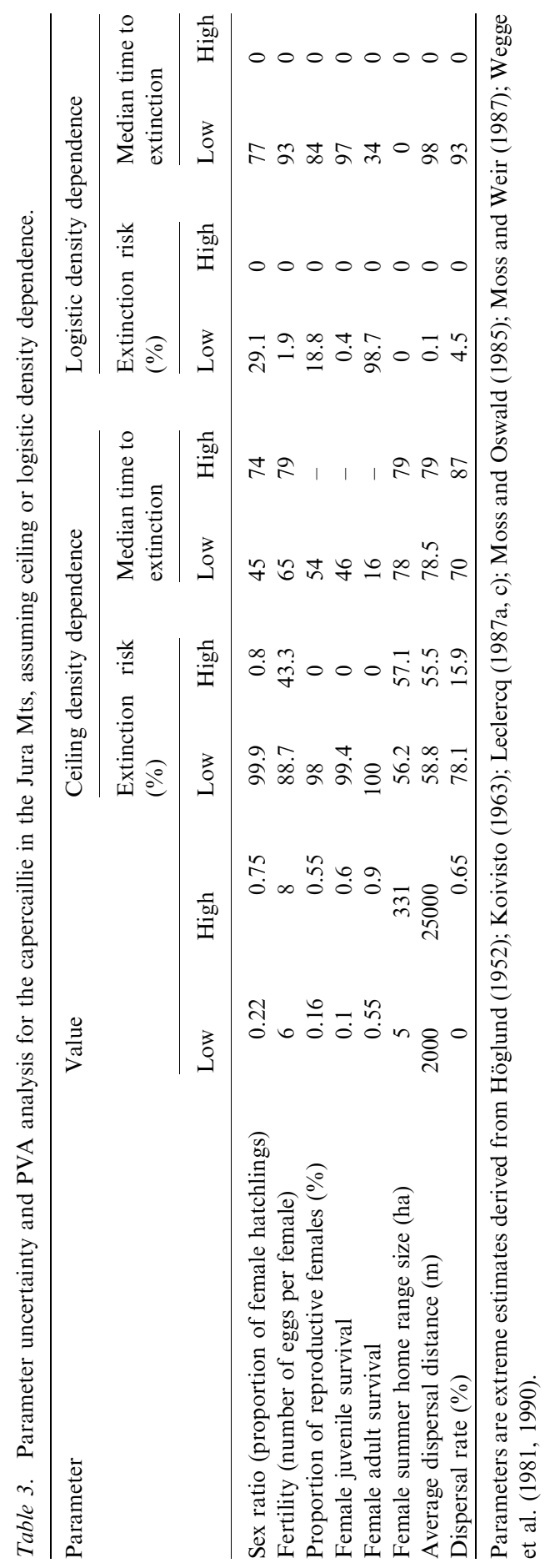


because the per capita growth rate increases as population decreases. The populations of capercaillie were severely endangered according to the baseline life-history traits assuming ceiling density dependence, with an extinction risk of $56.8 \%$, and a median time to extinction of 77 years. If logistic density dependence was assumed, a marginal risk of $0.05 \%$, and a median time to extinction of 99 years were recorded.

Uncertainty analyses also provided contrasted results depending on the shape of density dependence. Under ceiling assumptions, extinction risks proved to depend strongly on a series of parameters, among which female adult survival, sex ratio of broods, proportion of reproductive females, and female juvenile survival were the most important, followed by fertility (Table 3). Dispersal rate had a minor effect, but dispersal distance did not.

Under logistic density dependence, by contrast, adult survival was the single most important parameter affecting extinction risk (Table 3). Brood sex ratio and proportion of reproductive females had some effects, while all other parameters had only marginal effects if any.

\section{Management scenarios}

A first assessment with default parameters and annual decrease of the carrying capacity largely affected the risk analysis results (Table 4). The mean risk increased from 56.8 to $63.6 \%$ under the assumption of ceiling density dependence and from 0.05 to $18 \%$ in the case of logistic density dependence assumption.

An increase in available suitable habitats had a very small impact on estimated capercaillie persistence. Assuming ceiling density dependence, the risks were approximately the same as for the default simulation and around $50 \%$. Not unexpectedly, enhancing habitat for all 35 populations had the largest effect, reducing extinction risk to $45.4 \%$. If logistic density dependence was assumed, the risks were the same as for the default simulation, and close to $0 \%$.

Table 4. Results of a PVA examining habitat loss and improvements for the Jura capercaillie metapopulation, projected for 100 years.

\begin{tabular}{llllll}
\hline Scenario $^{\text {a }}$ & \multicolumn{2}{l}{ Ceiling density dependence } & & \multicolumn{2}{l}{ Logistic density dependence } \\
\cline { 2 - 3 } \cline { 5 - 6 } $\begin{array}{l}\text { Extinction } \\
\text { risk }(\%)\end{array}$ & $\begin{array}{l}\text { Median time } \\
\text { to extinction }\end{array}$ & & $\begin{array}{l}\text { Extinction } \\
\text { risk }(\%)\end{array}$ & $\begin{array}{l}\text { Median time } \\
\text { to extinction }\end{array}$ \\
\hline 1 & 63.6 & 76 & 18 & 92 \\
2 & 45.4 & 81 & 0 & 0 \\
3 & 52.7 & 79 & 0 & 0 \\
4 & 53.3 & 77 & 0 & 0 \\
\hline
\end{tabular}

${ }^{\mathrm{a}} \mathrm{K}$ is annually decreased by $0.43 \%$ in all populations (Scenario 1 ). $\mathrm{K}$ is increased by $50 \%$ for all populations (Scenario 2), in the two major populations (Scenario 3), in the 12 smaller populations (Scenario 4). 


\section{Discussion}

A widespread shortcoming of PVAs is the lack of accurate estimations of parameter means and variances (Reed et al. 1998). Despite the fact that the present analysis relied on an unusual 24-years long data base, specifically collected from the population we are modeling, the predicted extinction risks still varied largely, owing to uncertainties about some crucial assumptions in the model.

A large part of this variance was linked to uncertainty about the shape of density dependence: the logistic relationship predicted a less threatened future for capercaillie populations than did the ceiling relationship (an expected outcome since the logistic equation allows the per capita growth rate to increase as population declines; (Burgman et al. 1993). Lack of information about density dependence is a recurrent problem in PVA studies: though density dependence in reproduction or survival is known to play a crucial role in regulating population numbers (Sinclair 1989), its precise form and strength remains poorly documented in general, much debated and awaiting closer empirical scrutiny (Yearsley et al. 2003).

A linear decline of the per capita growth rate with density was documented in capercaillie (Cattadori et al. 2000), supporting the logistic option. In central Europe, the size and quality of capercaillie territories correlate negatively with density (Storch 1995), which should indeed generate a logistic response (a ceiling response would result from fixed territory size or quality). Regarding mechanisms, fecundity is unlikely to vary much with density in capercaillie, because female exhibit constant clutch size throughout the European distribution range, even in declining populations (Storaas and Wegge 1984). Juvenile recruitment, including both survival and access to reproduction, seems a more likely target. Many bird studies (though not all) document a decline in survival with increasing density (see Sinclair 1989 for a review), and juvenile birds often appear more vulnerable to breeding density and environmental disturbances in general (e.g., Both 1988). Capercaillie densities are currently low in the Jura Mts (Table 2) and thus very unlikely to affect juvenile birds' survival. By contrast, environmental disturbances strongly increased during the last decades (Ménoni 1994) and might largely decrease juvenile survival.

The shape and target of density dependence thus appears as a crucial empirical question for capercaillie conservation prospects. The (limited) support for a logistic relationship might appear as good news, given the outcome of our simulations, but the point remains that several factors likely to affect the extinction rate, including possible Allee effects (Burgman et al. 1993) for which we had no information, were not included in our simulations.

The most appropriate use of PVAs, however, does not lie in the absolute values of extinction risks provided, but in the ranking of threats and management options (Akçakaya and Altwood 1997), as well as sensitivities of lifehistory transitions. In this respect, adult female survival appears as the most important parameter acting on the viability of capercaillie populations, as is 
often the case in long-lived birds (Trouvilliez et al. 1988). However, recruitment also takes some importance, as expressed through a series of parameters including proportion of reproductive females, sex ratio of clutches, and juvenile survival. This result corroborates Moss et al. (2001) conclusions, who showed the overall decline of a Scottish capercaillie population to be due to a reduced recruitment of young birds as much as to an increased mortality of adults.

It is worth noting that recruitment took a particular importance under ceiling density dependence, i.e., under conditions of declining population and increased levels of local extinctions. This might partly stem from the spatial structure of the model: because dispersal is essentially a juvenile feature, recruitment might become a key parameter under non-equilibrium dynamics, since it provides the most effective way to counteract local patch extinction, by rescuing vanishing demes or recolonizing extinct patches. Accordingly, dispersal rate also significantly affected extinction risk under ceiling dependence (Table 3).

Source-sink dynamics seem a common feature of capercaillie populations in anthropogenic, fragmented landscapes (Segelbacher and Storch 2002). Despite their low numbers, immigrants appear essential to maintain the viability and genetic variability of small and isolated populations.

Dispersal distance, by contrast, had very limited effect, presumably because of the close spatial proximity of the several patches forming the metapopulation. Mean distance between two adjacent patches is $4.6 \pm 2.4 \mathrm{~km}$, while capercaillie dispersal abilities are well beyond this limit (Ménoni 1991). Within the present-day Jura network of patches, capercaillie dispersal abilities ensure correct connectivity for even the most remote of the occupied patches. Considering the small size and close geographical proximity of most suitable capercaillie habitat patches in the Jura Mts, it is likely that most small patches survive thanks to their connectivity to other populations (Sachot 2002).

Prospects obviously worsen if carrying capacity continues to decline at present rate (Table 4). Capercaillie need an open-forest structure (Sachot et al. 2003), and one important reason for its decline in the Jura may lie in the modifications of silvicultural and grazing practices over the last century (Leclercq 1987b), that led to the closing of the forest in many places. If this trend continues, the extinction risk will obviously become more serious, and the values provided in this study may underestimate real threats. However, as our simulations show (Table 4), stopping this trend or even reversing it appears insufficient to significantly improve survival chances. This must be accompanied by measures enhancing the quality of present-day habitat patches, thereby improving adult survival and recruitment (Table 3).

Adult survival in capercaillie is very sensitive to human disturbance, mainly during winter (Ménoni et al. 1994) while recruitment depends on many factors varying among years and sites (Leclercq 1987a), including climate (cold and rainy weather between April and June), insect availability, cables, predation, and human disturbance (Picozzi et al. 1999; Moss et al. 2001). 
One important action should be to limit human disturbance by restricting access into breeding and wintering sites. Despite detailed inquires, capercaillie collisions with fences and wires, recorded in France and Scotland as an important extra natural mortality factor, were presumed only in one Jura population at the end of the seventies (Leclercq 1987a). This probably results from the absence of fences within forests and long distances from ski station cables to present capercaillie populations. Predation can hardly be controlled directly. Summers et al. (2004) showed a moderate effect of crows and foxes control on capercaillie productivity, despite intense efforts. Larger scale and longer term predator control might have a stronger effect on capercaillie breeding success but this involves substantial additional material and financial resources. A positive indirect effects might result from forest management actions. Limiting forest fragmentation may efficiently control some predator species (Angelstam 1986), while maintaining an open structure to the forests will favor ground vegetation, thereby providing food for capercaillie and shelter from predators. Grouse-adapted forest management positively influence capercaillie and could act on food availability and predator numbers (Storch 1993).

Our results thus suggest that effective conservation will require several simultaneous actions, aimed at decreasing adult female mortality and increasing recruitment through enhancing habitat suitability. Besides limiting human perturbations, an appropriate silvicultural strategy should improve the quality and surface of present patches, independent of their size and localization. Preliminary attempts in the Jura Mts suggest that forest structure and composition can be improved through rejuvenation cutting at reasonable costs (S. Sachot, G. Dändliker, O. Schneider, unpublished data). However, action is required on a large geographic scale and over several years. Capercaillie populations, furthermore, may take some time before responding quantitatively. Thus, actions at the two levels delineated here above should be initiated rapidly if the Jura capercaillie population is to be saved.

\section{Acknowledgements}

We thank B. Leclercq and M. Montadert for access to long-term field data collected in population 21. A. Hirzel for his help during TetrasPool development and implementation. V. Grimm, I. Storch and J. Höglund, who tested previous versions of TetrasPool and provided useful comments. R. Akçakaya for helpful advices on life-history parameters and PVA calculations. I. Storch, I. Cattadori and two anonymous referees for their comments on earlier versions of this manuscript. MAVA Fondation and the Centre de Conservation de la faune et de la nature du canton de Vaud for funding and the University of Lausanne for logistic support. 


\section{References}

Akçakaya H.R. and Altwood J.L. 1997. A habitat-based metapopulation model of the California Gnatcatcher. Conserv. Biol. 11: 422-434.

Akçakaya H.R. and Baur B. 1996. Effects of population subdivision and catastrophes on the persistence of a land snail metapopulation. Oecologia 105: 475-483.

Angelstam P. 1986. Predation on ground nesting birds' nest in relation to predator densities and habitat edge. Oikos 47: 365-373.

Blair M., Bijlsma R. and Hagemeijer W. 1997. The EBCC Atlas of European Breeding Birds. T. \& A.D. Poyser, London.

Both C. 1988. Experimental evidence for density dependence of reproduction in great tit. J. Anim. Ecol. 67: 667-774.

Burgman M.A., Ferson S. and Akçakaya H.R. 1993. Risk Assessment in Conservation Biology. Chapman \& Hall, London.

Bustamante J. 1996. Population viability analysis of captive and released Beared Vulture populations. Conserv. Biol. 10: 822-831.

Cattadori I.M., Merler S. and Hudson P.J. 2000. Searching for mechanisms of synchrony in spatially structured gamebird populations. J. Anim. Ecol. 69: 620-638.

Crouse D.T., Crowder L.B. and Caswell H. 1987. A stage-based population model for loggerhead sea turtles and implications for conservation. Ecology 68: 1412-1423.

Dändliker G., Durand P., Naceur N. and Neet C. 1993. Contribution à l'étude et à la protection des grands tétras du Jura vaudois. In: Société vaudoise des Sciences naturelles (ed.), Le grand tétras Tetrao urogallus: statut et conservation des populations du Jura vaudois. Société vaudoise des Sciences naturelles, Le Brassus, Suisse, pp. 175-236.

Gjerde I. and Wegge P. 1989. Spacing pattern, habitat use and survival of capercaillie in a fragmented winter habitat. Ornis Scand. 20: 219-225.

Gutiérrez D., Thomas C.D. and Leon-Cortés J.L. 1999. Dispersal, distribution, patch network and metapopulation dynamics of the dingy skipper butterfly (Erynnis tages). Oecologia 121: 506-517.

Hanski I. 1991. Single-species metapopulations dynamics: concepts, models and observations. In: Hanski I. (ed.), Metapopulation Dynamics. Academic Press, London, pp. 17-38.

Hanski I., Moilanen A. and Gyllenberg M. 1996. Minimum viable metapopulation size. Am. Nat. 147: $527-541$

Höglund N. 1952. Capercaillie reproduction and climate. Pap. Game Res. 78-86.

IUCN 1996. Red List of Threatened Animals. IUCN, Gland, Switzerland.

Koivisto L. 1963. Über den Ortwechsel der Geschlechter beim Auerhuhn nach Markierungergebnissen. Volgelwarte 22: 75-79.

Leclercq B. 1987a. Ecologie et dynamique des populations du grand tétras (Tetrao urogallus major L.) dans le Jura français. Faculté des Sciences de la Vie. PhD, Université de Bourgogne, Dijon.

Leclercq B. 1987b. Influence des modes de gestion forestière passées sur la gestion actuelle et la structure des forêts de montagne ainsi que sur leurs peuplements en grand tétras. In: Actes du Colloque Galliformes de montagne. Gibier Faune Sauvage, Grenoble, France, pp. 265-282.

Leclercq B. 1987c. Premières données sur la comparaison de la dynamique des populations de grand tétras (Tetrao urogallus) et de gélinotte des bois (Bonasa bonasia) d'un même massif forestier du Haut-Jura. In: Actes du Colloque Galliformes de montagne. Gibier Faune Sauvage, Grenoble, France, pp. 21-36.

Ménoni E. 1991. Ecologie et dynamique des populations du grand tétras dans les Pyrénées, avec des références spéciales à la biologie de la reproduction chez les poules: quelques applications à sa conservation. PhD, Université Paul Sabatier, Toulouse.

Ménoni E. 1994. Plan de restauration du grand tétras (Tetrao urogallus) en France. Gibier Faune Sauvage 11: 159-202.

Ménoni E., Brenot J.F. and Catusse M. 1994. Grand tétras et ski de fond. Bull. mens. de l'ONC 190: $12-21$. 
Montadert M. and Chamouton A. 1997. Statut des tétraonidés dans le massif jurassien. In: Parc naturel régional du Haut-Jura (ed.), Secondes Rencontres Jurassiennes. Parc naturel régional du Haut-Jura, Prénovel. France, pp. 73-95.

Moss R. and Oswald J. 1985. Population dynamics of Capercaillie in a North-east Scottish glen. Ornis Scand. 16: 229-238.

Moss R., Oswald J. and Baines D. 2001. Climate change and breeding success: decline of the capercaillie in Scotland. J. Anim. Ecol. 70: 47-61.

Moss R. and Weir D.N. 1987. Demography of capercaillie Tetrao urogallus in north-east Scotland. II. Age and sex distribution. Ornis Scand. 18: 135-140.

Picozzi N., Catt D.C. and Moss R. 1992. Evaluation of capercaillie habitat. J. Appl. Ecol. 29: 751762.

Picozzi N., Moss R. and Kortland K. 1999. Diet and survival of capercaillie Tetrao urogallus chicks in Scotland. Wildlife Biol. 5: 11-23.

Reed J.M., Murphy D.D. and Brussard P.F. 1998. Efficacy of population viability analysis. Wildlife Soc. Bull. 26: 244-251.

Sachot S. 2000. TetrasPool. Version 1.0.2. Laboratory for Conservation Biology, Institute of Ecology, University of Lausanne, CH-1015 Lausanne, Switzerland.

Sachot S. 2002. Viabiliy and Management of an Endangered Capercaillie (Tetrao urogallus) Metapopulation. PhD, Faculté des sciences, Université de Lausanne, Suisse.

Sachot S., Perrin N. and Neet C. 2003. Winter habitat selection by two sympatric forest grouse in western Switzerland: implications for conservation. Biol. conserv. 112: 373-382.

Saether B.-E., Engen S., Swenson J.E., Bakke O. and Sandegren F. 1998. Assessing the viability of Scandinavian brown bear, Ursus arctos, populations: the effects of uncertain parameter estimates. Oikos 83: 403-416.

Schifferli A., Géroudet P. and Winkler R. 1980. Atlas des oiseaux nicheurs de Suisse. Station ornithologique suisse, Sempach.

Schmid H., Luder R., Naef-Danzer B., Graf R. and Zbinden N. 1998. Atlas des oiseaux nicheurs de Suisse. Station ornithologique suisse, Sempach.

Segelbacher G. and Storch I. 2002. Capercaillie in the Alps: genetics evidence of metapopulation structure and population decline. Mol. Ecol. 11: 1669-1677.

Sinclair A. 1989. Population regulation in animals. In: Cherett J.M. (ed.), Ecol. Concepts. Blackwell Scientific Publications, Oxford, pp. 197-241.

Storaas T. and Wegge P. 1984. High nest losses in capercaillie and black grouse in Norway. In: Lovel T.W.I. and Hudson P.J. (eds), Third International Grouse Symposium. C.I.C. World Pheasants Association, York, pp. 481-492.

Storch I. 1991. Habitat fragmentation, nest site selection, and nest predation risk in Capercaillie. Ornis Scand. 22: 213-217.

Storch I. 1993. Habitat use and spacing of capercaillie in relation to forest fragmentation patterns. PhD. Faculty of Biology, Université Ludwig-Maximilian, Munich.

Storch I. 1995. Annual home ranges and spacing patterns of capercaillie in central Europe. J. Wildlife Manage. 59: 392-400.

Storch I. (compiler) 2000. Grouse Status Survey and Conservation Action Plan. WPA/Birdlife/SSC Grouse Specialist Group. IUCN, Gland, Switzerland and the World Pheasant Associations, Reading, UK.

Summer R.W., Green, R.E., Proctor R., Dugan D., Lambie D., Moncrieff R., Moss R. and Baines D. 2004. An experimental study of the effects of predation on the breeding productivity of capercaillie and black grouse. J. Appl. Ecol. 41: 513-525.

Trouvilliez J., Gaillard J.M., Allaine D. and Pontier D. 1988. Stratégies démographiques et gestion des populations chez les oiseaux: particularités des Galliformes. Gibier Faune Sauvage 5: 27-41.

Wegge P., Gjerde I., Kastdalen J., Rolstad J. and Storaas T. 1990. Natural mortality and predation of adult capercaillie in south-east Norway. In: Proceeding of the International Symposium on Grouse, pp. 49-56. 
Wegge P., Larsen B. and Storaas T. 1981. Dispersion printanière d'une population de coqs de bruyère dans le sud-est de la Norvège. In: Kempf C. (ed.), Actes du Colloque International Grand Tétras. Union Nationale des Associations Ornithologiques, Colmar, France, pp. 138-153. Yearsley J.M., Fletcher D. and Hunter C. 2003. Sensitivity analysis of equilibrium population size in a density-dependent model for Short-tailed Shearwaters. Ecol. Model. 163: 119-129. 